\title{
Gobierno abierto y gobernanza del agua:
} 17 de octubre de 2021

\section{promesas y desafíos}
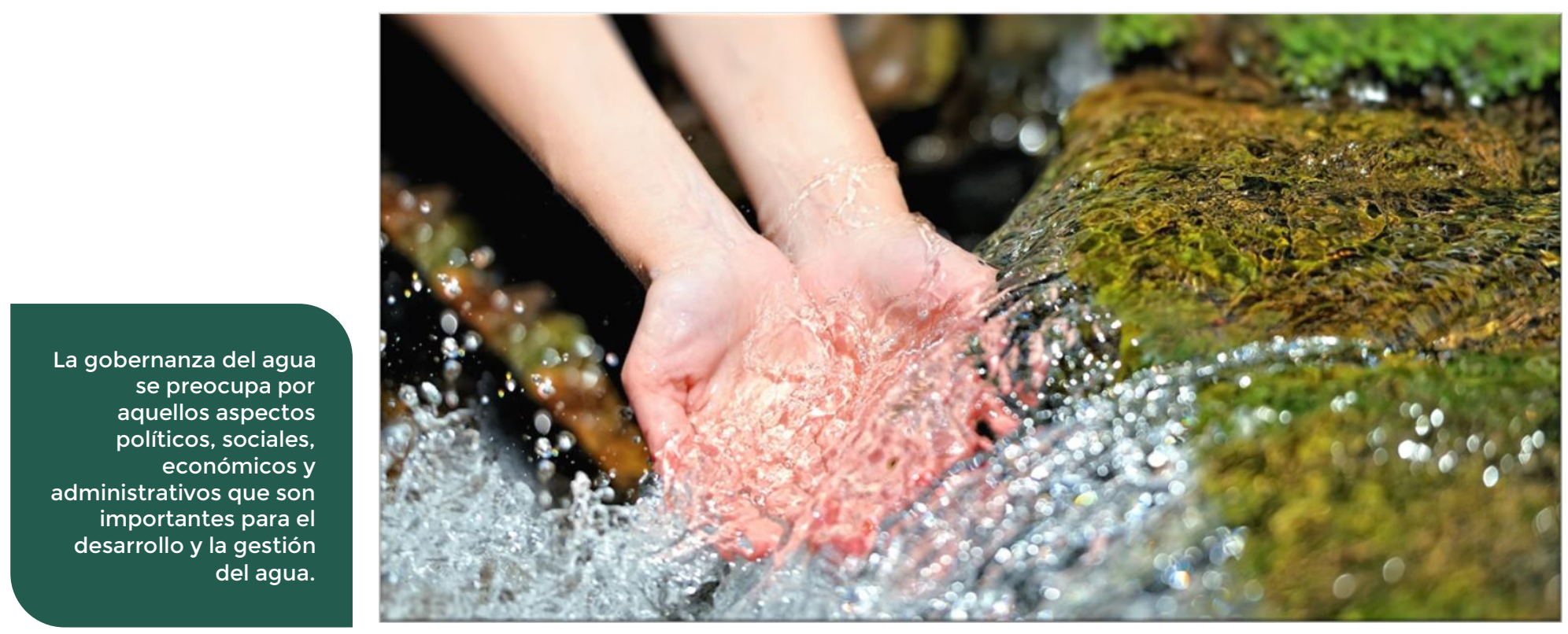

El gobierno abierto es una nueva filosofía de gobierno que implica una gestión pública más transparente y participativa entre el Estado y la sociedad y que refuerza aspectos deliberativos.

Se sustenta en tres pilares: 1) transmitir información a la sociedad, 2) promover la participación, y 3) construir colaboración entre la sociedad y el Gobierno (Salgado, 2021).

En los últimos años, esta nueva dirección centrada en el ciudadano ha cobrado auge, en parte a causa de la demanda de apertura y de participación que desde hace algunas décadas se ha dado en diversos lugares del mundo como parte de las transformaciones del sistema democrático, pero también debido al interés de algunos gobiernos para generar confianza entre la sociedad.

De acuerdo con Cruz (2015), el gobierno abierto es una filosofía político-administrativa que se basa en los valores y principios de la transparencia, de la democracia participativa, del empoderamiento ciudadano, de la rendición de cuentas, del open data y del uso de avances tecnológicos, que constituye un modo de implementación, control y evaluación de políticas públicas y de procesos de modernización administrativa.

Estos procesos se sustentan en el uso de las tecnologías de la información y la comunicación (TIC), lo que ha llevado a confundir esta filosofía de gobierno simplemente como un nuevo desarrollo tecnológico que usan los gobiernos. En tal sentido, el gobierno abierto frecuentemente es confundido 
con el llamado e-government (también conocido como e-administración o gobierno electrónico), que se refiere justamente a la aplicación de las TIC y sus herramientas a los procedimientos administrativos preexistentes, es decir, a la tecnificación de procesos en la administración pública (Calderón y Sebastián, 2010).

Sin embargo, el gobierno abierto consiste en un cambio de valores y de la forma de concebir la política. Desde nuestra perspectiva, ello posibilita una transformación y la construcción de nuevas formas democráticas, las cuales se verán en la siguiente sección.

\section{Las promesas}

La construcción de un gobierno abierto puede habilitar nuevas formas de interrelación entre Gobierno y sociedad, ya que permite:

1) La creación de espacios para la expresión política. Al ser una nueva forma de espacio público y de interacción entre gobierno y sociedad propician nuevas formas de participación que pueden llevar a cambiar o mejorar condiciones existentes.

2) La exigibilidad de derechos, pues la apertura de espacios públicos alienta el reconocimiento y el ejercicio de derechos, como el derecho al agua, así como la búsqueda de la inclusión en la toma de decisiones con respecto a la distribución del agua. Desde esta perspectiva, el ciudadano, más que un portador de derechos, se puede transformar en un sujeto de reclamos efectivos.

3) Un espacio de construcción y de cambio. La búsqueda constante de los ciudadanos para alcanzar los derechos plenos es un proceso dinámico, ya que la interlocución constante crea nuevos horizontes de cambio.

4) Reinventar y reorganizar el gobierno, pues implica un cambio en la reingeniería de procesos, de la organización administrativa y de la relación con la población. Asimismo, si partimos de que el gobierno abierto implica un cambio de valores en el cual se privilegia escuchar las demandas de la población y generar estrategias para mejorar la relación de confianza, se colocan como aspectos fundamentales los tres pilares mencionados al principio: información, participación y colaboración.

Las anteriores consideraciones se enmarcan en un marco aspiracional, bajo una promesa de un gobierno democrático; sin embargo, en la práctica es más complejo, en términos de la gobernanza del agua.

\section{Los desafíos}

Dadas las complejidades del uso del agua en la sociedad, se requiere que las voces dispares sean escuchadas y respetadas en las decisiones sobre las aguas comunes y el uso de los escasos recursos financieros y humanos con el fin de asignar el agua de manera equitativa y eficiente, asegurando la sostenibilidad ambiental. La gobernanza del agua se preocupa por aquellos aspectos políticos, sociales, económicos y administrativos que son importantes para el desarrollo y la gestión del agua.

Si bien los tres pilares que hemos mencionado al principio: información, participación y colaboración, promueven la elaboración de acuerdos sociales a través de la incorporación de la sociedad en la toma de decisiones, cómo ya se dijo, en la práctica no es fácil. En este sentido, pese a los esfuerzos de algunos gobiernos, aún se presentan deficiencias en materia de transparencia, participación ciudadana y colaboración. La dificultad para acceder a información básica sobre la calidad del agua y los parámetros 
usados para su medición, el estado de las redes de distribución, y en general sobre los sistemas de acueducto, impide que los ciudadanos puedan participar activamente. Ejemplo de ello son los casos que se presentaron en el evento Transparencia Hídrica y Gobierno Abierto. Experiencias Internacionales, que se llevó a cabo en línea el pasado 15 de octubre a través del Espacio de Conocimiento del Instituto Mexicano de Tecnología del Agua.

Asimismo, a pesar de que el agua es un sector que afecta directamente la calidad de vida de las personas, todavía presenta grandes deficiencias en cuanto a la generación y apertura de información (ver las ponencias de Lucia de Stefano y Nuria Hernández).

Adicionalmente, otro de los retos del gobierno abierto se refiere, justamente, al uso de las herramientas que utiliza para su interlocución con la sociedad, en el que se privilegia el intercambio de información a través de las tecnologías. Es importante reconocer que, al menos en nuestro país, una parte de la población vive en zonas rurales sin acceso a las tecnologías, lo cual genera escenarios de desigualdad y aumenta las brechas de inequidad en el acceso al agua.

Pese a los anteriores señalamientos, el gobierno abierto, como una filosofía de gobierno, abre las posibilidades a nuevos espacios de interlocución para la democracia deliberativa en el sentido de que escucha las necesidades de información, fomenta la participación mediante nuevos espacios políticos y crea consensos encaminados a un bien general. Sin embargo, este es aún un camino en construcción.

Acceso al video del Espacio de Conocimiento: Transparencia Hídrica y Gobierno Abierto. Experiencias Internacionales del 15 de octubre de 2021. (https://www.youtube.com/watch?v=V6xoRmaG9Zw)

Referencias:

Cruz, C. (2015). ¿Qué es (y que no es) gobierno abierto? Una discusión conceptual. Economía Revista en Cultura de la Legalidad. 8. 37-53.

Calderón, C. y Sebastián, L. (2010.). Open Government: Gobierno abierto. Jaén, España: Algón Editores MMX, 2010.

Salgado, A. (2021) Gobierno abierto, Perspectivas, Instituto Mexicano de Tecnología del Agua 